\title{
ANNOTATIONS
}

\section{Dangerous Colour-Blindness}

A simple test for the segregation of those whose colour-blindness is of such a nature as to render them dangerous in navigating ships or driving railway trains has been long sought. In another column we publish a report to the Board of Trade on the Standard of Rejection for Colour-blindness for Seamen by Dr. F. W. Edridge-Green. All will agree that " any one who can distinguish between the red, green, and white lights at a distance of a mile has sufficiently good colour perception for the purpose of navigation at sea." Dr. Edridge-Green states that "about 5 per cent. of men will fail to distinguish between the red, green, and white lights of a properly constructed lantern, or with the actual lights themselves at a distance of a mile," and that " the lantern is therefore an efficient test." He supports his views with a re-statement of some parts of his familiar theories, and adds " it will be noticed that this standard is based only on facts." In our opinion this is a strained and unjustifiable use of the term " facts," but more important is the absence of any definite " standard." For difficulties immediately arise in practice. As laid down by the Departmental Committee of the Board of Trade (Cd. 6256) " if a candidate mistakes a red light for a green or vice versa he should be considered to have failed. . . . Other mistakes should be referred to the Board of Trade to determine whether any further examination is necessary." 'The " other mistakes " are: calling white red or green, calling red or green white, and none of these is uncommon. Further examination by suitable spectroscopic tests proves that these mistakes may be either trivial or serious, yet the lantern alone cannot definitely decide. Where then is the standard? The Departmental Committee rightly concluded that while the lantern test was excellent and sufficient to eliminate the worst cases of colour-blindness - those who call red green or vice versa-other cases demanded further examination by methods which could be applied only by experts. The panel of examiners for these " referred cases " included a nautical adviser, a physicist, and an ophthalmic surgeon. The Board of Trade adopted the recommendations of their Departmental Committee and these were in force until the appointment of Dr. Edridge-Green as a Special Examiner in 1920. As is well known, this appointment was tantamount to abandoning the recommendations of the Departmental Committee. The Board of Trade have hitherto given no reasons for taking this drastic and autocratic step. Dr. Edridge-Green's report cannot but raise grave doubts as to the efficiency of the methods now in use. 